\title{
Learning in Online Communities: Behavioral Strategies of the Users of Educational Social Networks
}

\author{
Aleksei N. Sergeev*
}

Volgograd State Socio-Pedagogical University, Volgograd, Russian Federation

\begin{abstract}
The article deals with the results of a study on users' behavioral strategies in educational social networks as Internet platforms for the communities of students and teachers who collaborate to solve educational problems. According to the analysis of the students and teachers' activity on the educational social network of the Volgograd State Socio-Pedagogical University, the author has determined the groups of users with similar behavioral strategies, namely: community organizers, activists for communication and document exchange, educational assignment performers, information consumers, and inactive users. The author provides generalized portraits of each group, their numerical composition, as well as comparative characteristics in relation to other groups. The manuscript concludes that the presented groups reveal typical behavioral strategies of the users of educational social networks, which further development of educational platform tools, as well as pedagogical technologies based on their implementation should consider.
\end{abstract}

Keywords: Education, Internet, social network, online community, student, teacher.

\section{INTRODUCTION}

Education employs internet technologies extensively. Internet resources provide teachers and students with access to educational information, means of remote communication, and opportunities for collaboration, new resources development, and selfrealization in the framework of developing information environment. Currently, the social networking services fully implement these aspects by maintaining the work of individual users and Internet communities. These areas of pedagogy are actively investigated by Russian (Andreev, 2011; Patarakim, 2017; Lebedeva, 2015; Khutorskoy, 2019) and foreign (Mikropoulos and Natsis, 2011; Carmichael, 2011; João Ferreira et al., 2015; FICCI Higher Education Committee, 2017; Klopp and Abke, 2018) teachers and researchers.

The idea of joint educational activity in students and teachers' communities can form the basis for the development of learning platforms for certain educational organizations. In particular, it is due to the implementation of well-known services of social networks in education (Manca, 2020; Sebo and Haskova, 2020; Marquis, 2017; Al-Azawei, 2019; Aleksandrova and Parusheva, 2017; Kalischuk, 2017; Tkachenko and Bogatyreva, 2017), as well as to the creation of corporate educational portals based on the ideas of the development of educational social networks (Bykov and Litvinova, 2016; Vlasova, 2018; Mikhailichenko and Vitkevich, 2019; Ivanko et al., 2019; Sebo, 2016).

*Address correspondence to this author at the Volgograd State SocioPedagogical University, Volgograd, Russian Federation;

E-mail: reseacher sergeev@mail.ru
An educational social network is an educational portal, which, introduces students and teachers, as well as various tools for their collaboration, work with common digital resources, interaction with digital learning systems, and acquired knowledge control. However, the availability of these tools provides the users with the choice of various behavioral strategies, and methods of learning activities related to teaching and learning. How can it influence on the differentiation of the users? Is it possible to define their typology in order to describe typical strategies? What tools of the educational portals are in demand by the members of educational communities and how these tools correlate? Answers to these questions would provide new understanding of the character of learning activities in Internet communities, as well as reveal means for the applied tools improvement.

\section{METHODOLOGY}

The authors of the present research have analyzed users' work on educational platform, which is based on the implementation of learning in Internet communities, namely the educational portal of the Volgograd State Socio-Pedagogical University (VSSPU).

The educational portal of VSSPU is an educational social network, which represents students and teachers, who are tending to solve educational problems. A complete set of instruments for social network platforms is implemented on the portal, such as tools for the development of personal pages and friendly relations, interpersonal messaging system, statuses publication, group work organization, etc. In addition, specialized tools for educational process are 
introduced, namely: platform for e-courses implementation, knowledge testing system, tools for preparing, checking and evaluating reports on educational assignments, etc. The portal is based on the WordPress content management system with the BuddyPress social network plugin, as well as a series of other plugins that provide the implementation of individual features and stand-alone services of the educational portal.

In the context of the present research, the authors analyzed the work of the students and teachers, who accessed the portal in academic year 2019/2020. As a result, indicators, characterizing the implementation cases and intensity of the tools educational social networks, were determined:

1. Duration of work on the site;

2. The existence or absence of a personal avatar;

3. Number of friends;

4. The number of groups the user is subscribed to;

5. The number of; new groups that were developed by the user;

6. The number of documents uploaded by the user;

7. The number of published statuses;

8. The number of posts written on group forums;

9. The number of private messages sent or received by the user;

10. The number of training courses the user has subscribed to;

11. The Number of developed training courses;

12. The number of training reports sent to teachers;

13. The number of tests performed.

To determine the values of these indicators, WordPress plugins were created that allow you to get statistics on the operation of a social network and stand-alone service sites, to offer these statistics in a numerical tabular format while maintaining the anonymity of the work of specific users.

In terms of the statistical analysis, the authors were focused on the existence of certain qualitative deviations in the identified values, which make it possible to determine groups of users with a specific behavioral strategy. When a certain group had been distinguished and characterized, the research focused on the rest of the users.

\section{RESULTS}

During the analyzed period, 6,955 people accessed the resources of the educational portal. Among them, 3,418 people registered on the portal in 2019/2020 academic year (novice users), the rest of the users were registered earlier (experienced users).

Among novice users, 357 people worked with the site only once, i.e., on the day of registration. However, many of these one-day work users expressed conscious activity, namely: joined groups (39 people), established friendly relations (33 people), set a personal avatar (16 people), used private messaging system (26 people), uploaded documents (four people), published personal status (60 people), subscribed to some courses (40 people), and even sent training reports (five people). In general, 138 one-day work users demonstrated conscious activity. However, these users did not access the portal any more.

The phenomenon of one-day work users was caused by educational character of the portal (the users followed the teacher's instructions and performed certain tasks there), the necessity to register on the portal to communicate with a specific person, and by the fact that in some cases the portal was subjected to external attacks (publication of advertising messages).

Excluding the users who worked on the portal only once, 6,599 people could be referred to active users of the portal in the analyzed academic year. Among them, 3,536 people were experienced users and 3,063 people were novice users.

Figure 1 shows statistics on the application of portal tools by active users. According to these data, the most frequently used features of the educational social network are the following:

1. E-courses study $(4,882$ people);

2. Participation in groups (4,786 people);

3. Establishing friendly relations with other users of the portal $(3,828$ people $)$;

4. Sending training report to a teacher $(3,520$ people). 


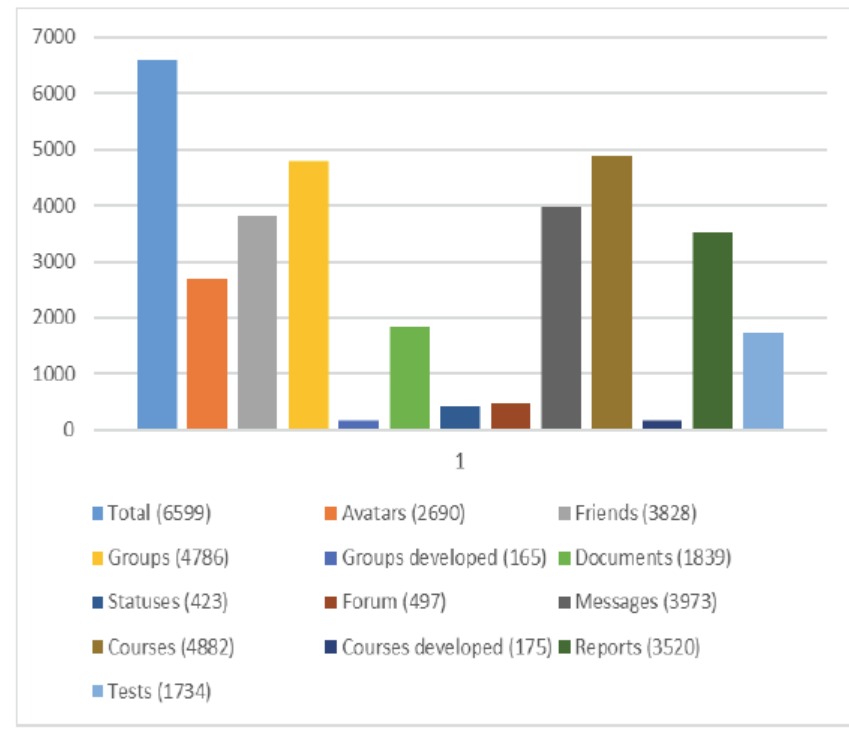

Figure 1: The utilization of social network tools by active users of an educational portal.

Additionally, the statistics of the frequency of the portal tools application are also worth studying. The information on the average number of particular tool hits for the users who applied it at least once is introduced in Figure 2.

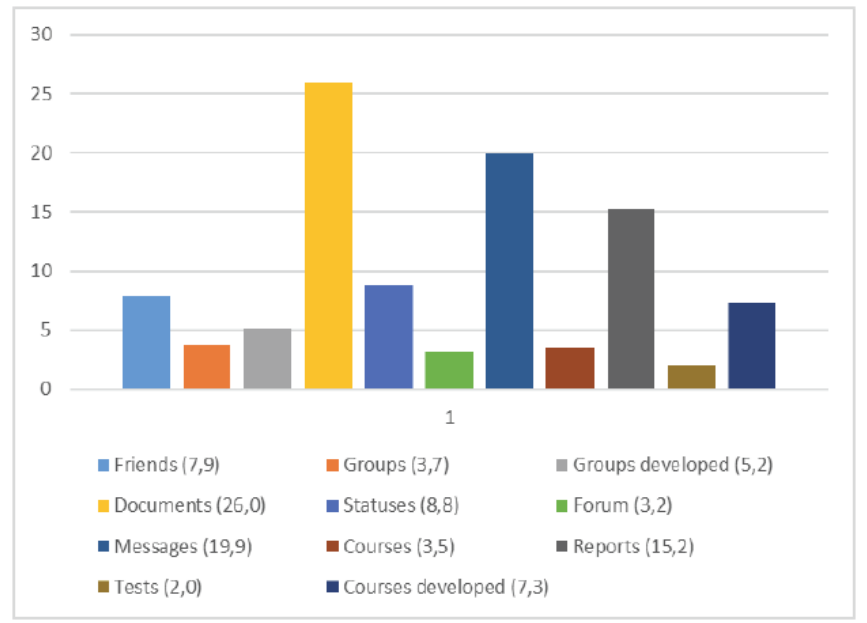

Figure 2: The frequency of the social network tools application by active users of an educational portal.

The presented data show that, on average, each user, who accesses certain tool on the site, has the following indicators of the tools use intensity:

1. Has approximately eight friends;

2. Is subscribed to three or four groups;

3. Has uploaded approximately 26 documents;

4. Has written approximately nine statuses;
5. Has written approximately three posts on the forums;

6. Has sent or received approximately 20 private messages;

7. Has subscribed to three or four e-courses;

8. Has sent more than 15 training reports to teachers;

9. Has completed two tests.

According to the comparison of this data with the values for the tools utilization, the tools ratings in terms of utilization and intensity do not coincide. For example, some course and group subscriptions with wide array of options are not in demand in terms of usage. In addition, the tool for document publication, which is the most intensively, used one, ranked only the seventh in the utilization rating.

Tools for sending private messages and educational reports to teachers have high positions in terms of both utilization and intensity. These tools implement the possibilities for personal interaction of the portal users. However, the tools for statuses publishing and forums communication have weak positions of utilization and intensity. It is worth emphasizing, that these tools allow communication in public space.

A sophisticated analysis of such situations allowed us to identify groups of portal users with special behavioral strategies. We provide the characteristics of these groups.

\section{Community Organizers}

The least popular is the possibility of creating new courses and groups. These resources are used by 175 and 165 people, respectively. Since some users develop both groups and courses, their total number is 274 people. This fact is worth emphasizing, as the creation of new courses and groups, as well as corresponding educational opportunities in the Internet communities, are on opposite places in the rating list of social network tools. Additionally, the analysis of statistics shows that each user, who developed new courses or groups, did it more frequently than all portal users became their members.

Thus, the possibilities of creating new courses and groups, which were not in demand among the users of the educational social network, became a special tool 
for organizing new communities and a base for education implementation in a digital environment. Users who perform this work are the most active users of the educational social network. They are effective in filling the learning portal with educational materials, organizing the learning community, and implementing the learning process.

We present a generalized portrait of a community organizer. This is a user who has been working on the site for more than two years, has a personal avatar, has established friendly relations with approximately 33 other users, has subscribed to five or six groups, three of which they developed themselves, and has subscribed to six or seven e-courses, being the author of four or five of those courses. In three of four cases, community organizers have used a private messaging system. On average, each user has written or received approximately 128 letters.

In two out of three cases, community organizers have published their documents, uploading almost 110 of them to their personal pages and groups. In approximately a quarter of the cases, community organizers have published at least 17 statuses. In only one of 12 cases, community organizers have posted messages on the forums; each of them has written approximately 13 messages. Community organizers, being e-courses subscribers, sent training reports and passed digital tests. Thus, every seventh community organizer sent three to four reports and passed two to three tests.

Comprehensive statistics of the community organizers' work are presented in Table 1 (first section). The introduced characteristics are average for all community organizers. It is worth highlighting that usage patterns for portal tools vary greatly for individual members of the group. To the greatest extent, this concerns the following aspects:

The number of received and sent messages (the least active users (20 people) wrote and received 25 messages, and the most active ones (20 people) more than 15 thousand messages);

- Published documents (the least active (20 people) published 46 documents, and the most active (20 people) almost 9 thousand documents);

The number of friends (20 and 4,500 friends for 20 the least and the most active users respectively).
The presented characteristics can be advantageous in the context of in-depth study of the peculiarities of the portal tools application by community organizers' in educational social networks.

\section{Activists for Communication and Document Exchange}

After identifying and describing community organizers as a group of portal users, further research was carried out in terms of identifying a group of active users who do not develop communities, despite the fact that they do use tools of educational social network for communicating with other portal users and for sharing documents.

The users, who applied at least one tool from the list below more actively in comparison to other users, were attributed as activists for communication and document exchange:

1. Document uploading;

2. Statuses posting;

3. Communication in the forum;

4. Interpersonal messaging.

For each instrument, the median value was determined, considering only those users who applied the tool on at least one occasion. Only those users, for whom the number of hits to the tools was higher than the median value, were regarded as active users.

By adopting the aforementioned approach, we have identified a group of users, namely, activists for communication and document exchange. The group consisted of 2108 people. Comprehensive statistics of their work are presented in the second section of Table 1.

The generalized portrait of activists for communication and documents exchange is as follows: On average, these users have been on the site for about two years. They have a personal avatar in roughly half of these instances. These users establish friendly relations (three quarters of the users) and actively subscribe to groups (every six users out of seven). Each such user has four to five friends, and is subscribed to three or four groups. Activists for communication and document exchange refer to a private messaging system on a more frequent basis than community organizers (in four of five cases). However, the number of messages sent or received is significantly less. 
On average, it is about 20 . The name of the group under study just emphasizes its foreground activity, although the activists for communication and documents exchange are inferior to community organizers in terms of application of the tools designed for communication and information exchange. They upload their documents in slightly more than half of the cases, update statuses in about one case of seven, and post messages on the forum in one case of six. Users, who utilize the indicated tools, publish approximately 27 documents, update their status three or four times, and post seven messages on the forums.

Activists for communication and document exchange effectively apply the means of educational process implementation on educational portal. In six of seven cases, they are subscribed to e-courses (on average, for four courses). In two of three cases, they send training reports; in every third case, they perform tests. On average, each such user submits 19 to 20 reports and performs two tests.

\section{Educational Assignment Performers}

The users who did not interact much with other users of the portal, although they were active in studying, and following teachers' instructions, represent a significant part of the present group. They prepared and sent reports on training sessions, and performed tests. This group consists of 892 users. Comprehensive statistics of their work are introduced in the third section of Table 1.

A generalized portrait of educational assignment performers is as follows. These are users, who have been on the site for two years on average. In only a third of the cases, they upload a personal avatar, and establish friendly relations in half of the cases (approximately five friends). In $70 \%$ of the cases they subscribe to some groups (two or three groups), but in $85 \%$ of the cases they take training courses (four or five courses). In only half of the cases, they use private messaging system, having received and sent approximately three letters. They publish statuses rarely (in $2.42 \%$ of cases, i.e., one status on average). The system of documents sharing is used more actively. Every fifth user publishes four or five documents.

As it is implied in the name of the group, active work is conducted by means of the tools for training reports preparing and the performance of tests. The users, i.e., the educational assignment performers, do the teachers' assignments in four of five cases (on average, 25 reports are prepared by each user); and in about half of the cases they perform tests. On average, each user passes approximately three tests. These indicators are significantly higher than for the users of the group of activists for communication and documents exchange. The index of subscription to courses is also higher, in terms of both utilization and intensity of this tool application.

\section{Information Consumers}

The next part of the study dealt with the users who did not interact actively with other users of the portal, and were not effective in educational tasks performance. However, they actively used the proposed resources to access the information. We have identified the existence of friends, subscription to groups and courses as distinctive features of such users. This choice is conditioned by the fact that friendly relations establishment, as well as the subscription to the communities, technically means "connecting" the user to the streams of information published in the user's profiles, groups, and training courses. The group of information consumers includes 1,659 portal users. The statistics of such users' work are presented in the fourth section of Table 1.

As it was expected, the indexes of the implementation of communication tools and information exchange are significantly inferior to those of the groups, which were described above. The generalized portrait of the information consumers is as follows. On average, these are users, who have been on the portal for more than two years. In only two of five cases, they have a personal avatar, and in three of five cases, they establish friendly relations (five or six friends). In four of five cases, they subscribe to groups (three or four groups) and training courses (on average, just over two courses). In only a third of the cases, they refer to private messaging system, i.e., they send or receive less than three messages. Approximately every eighth user uploads documents (just over four documents). Statuses are published extremely rarely, i.e., every fiftieth user publishes only one status.

Despite low public activity, the users of this category work with published information on a regular basis. It is worth emphasizing that the users of this category subscribe to other users' timelines and groups (establishment of friendly relations) more actively than the educational assignment performers. The indexes of subscription to courses and work with documents are not inferior much. 
Despite the fact that one-tenth of the users of the category under study have less than two months experience on the site, every two out of five users have worked on the site for more than two years. Therefore, behavioral strategy based on the access to information can be steady enough.

\section{Inactive Users}

The last distinguished group consists of the users, who performed low activity in applying the portal tools. Their total number is 1,568 people. Comprehensive statistics of their work are introduced in the fifth section of Table 1.

According to the statistics, inactive users have a personal avatar in only every fifth case; use the system of private messages with almost the same frequency (two or three messages). They update statuses rarely ( $1 \%$ of cases, i.e., one entry on average). The document publishing system is used more actively, i.e., in $6 \%$ of cases (on average, three documents). The possibility of subscribing to groups is rather actively used. Thus, about a half of inactive users is subscribed to one, and sometimes two groups. The situation with regard to electronic courses is almost the same. Approximately half of inactive users have a subscription (one or two courses). Every third user sends training reports (on average, four or five reports are prepared and sent); and every tenth user works with tests (completed one test).

It is worthy emphasizing that 145 inactive users did not perform any activity during the study period. Moreover, their average presence on the site was approximately a year. This phenomenon is determined by the fact that the users applied other portal tools, which were not analyzed in the present article (working with blogs, tool systems for documents development, etc.). In addition, users who would utilize portal actively, although accessed the portal only occasionally during the studied academic year, were also referred to inactive users.

\section{CONCLUSION}

Thus, in the course of the study, we distinguished and described five groups of educational portal users. The last is an educational social network that ensures the functioning and educational activity of network communities:

1. Community organizers;
2. Activists for communication and document exchange;

3. Educational assignment performers;

4. Information consumers;

5. Inactive users.

The ratios of the numbers of all these groups are clearly presented in Figure $\mathbf{3}$. The demand for various tools in these groups can be estimated from Figure 4 .

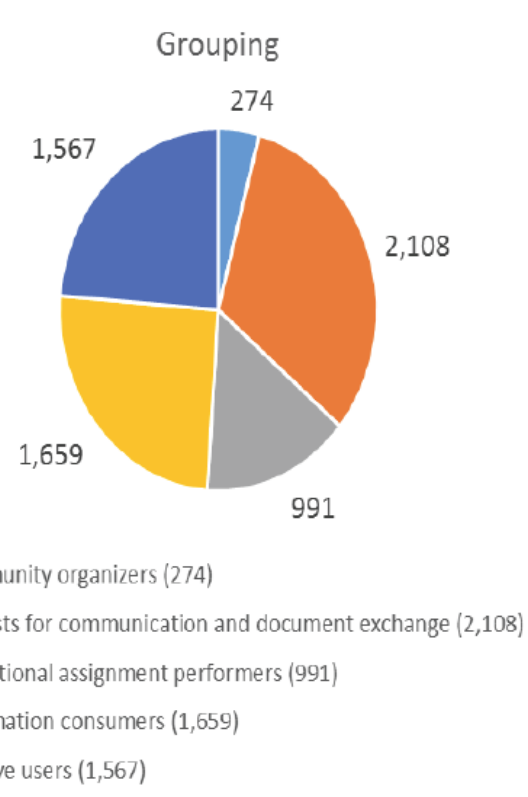

Figure 3: User groups of an educational social network.

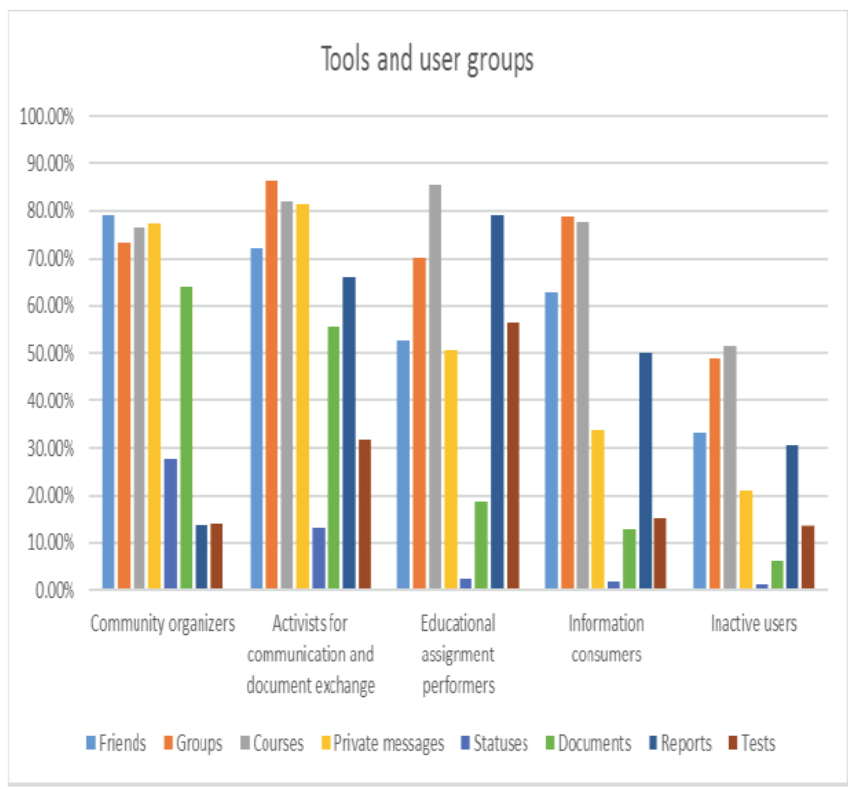

Figure 4: Demand for the tools of an educational social network according to the group of users. 
Table 1: The Utilization and Intensity of the Application of the Tools of an Educational Social Network According to the Portal User Groups

\begin{tabular}{|c|c|c|c|c|c|c|c|c|}
\hline & $\begin{array}{l}\frac{0}{0} \\
\frac{0}{0} \\
\frac{0}{L}\end{array}$ & $\begin{array}{l}\text { 윽 } \\
\text { ㅇํㄴ }\end{array}$ & 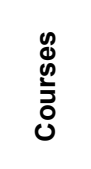 & 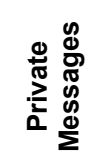 & 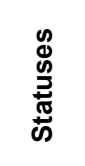 & 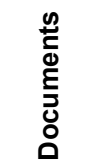 & 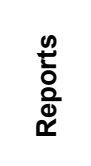 & 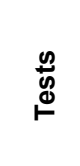 \\
\hline \multicolumn{9}{|c|}{ 1. Community organizers (274 people) } \\
\hline Scope $(\%)$ & 79.20 & 73.36 & 76.64 & 77.37 & 27.74 & 63.87 & 13.87 & 14.23 \\
\hline Intensity (units) & 41.42 & 7.39 & 8.6 & 128.16 & 17.32 & 109.49 & 6.39 & 2.38 \\
\hline \multicolumn{9}{|c|}{ 2. Activists for communication and document exchange (2,108 people) } \\
\hline Scope $(\%)$ & 72.34 & 86.15 & 82.12 & 81.45 & 13.05 & 55.65 & 65.80 & 31.64 \\
\hline Intensity (units) & 6.24 & 3.89 & 3.88 & 20.33 & 3.46 & 27.32 & 19.45 & 2.07 \\
\hline \multicolumn{9}{|c|}{ 3. Educational assignment performers (991 people) } \\
\hline Scope $(\%)$ & 52.77 & 70.13 & 85.47 & 50.55 & 2.42 & 18.67 & 79.11 & 56.51 \\
\hline Intensity (units) & 4.92 & 2.78 & 4.42 & 3.06 & 1 & 4.30 & 25.38 & 2.85 \\
\hline \multicolumn{9}{|c|}{ 4. Information consumers (1,659 people) } \\
\hline Scope $(\%)$ & 62.81 & 78.78 & 77.64 & 33.63 & 1.81 & 12.72 & 50.21 & 15.43 \\
\hline Intensity (units) & 5.65 & 3.50 & 2.30 & 2.81 & 1 & 4.13 & 5.18 & 1 \\
\hline \multicolumn{9}{|c|}{ 5. Inactive users (1,567 people) } \\
\hline Scope $(\%)$ & 33.29 & 48.92 & 51.40 & 21.17 & 1.15 & 6.06 & 30.48 & 13.52 \\
\hline Intensity (units) & 1.80 & 1.33 & 1.36 & 2.72 & 1 & 3.03 & 4.46 & 1 \\
\hline
\end{tabular}

Statistical data on the utilization and intensity of the application of the tools of educational social network according to the portal user groups are introduced in Table 1.

The conducted research proved that the ways the resources of the educational social network are applied by portal users vary greatly. For about a quarter of users (inactive users), the educational portal is a technical platform for solving particular educational problems and for occasional work with other users and published information. The second quarter of users (information consumers) apply the portal resources consistently, although only in a passive mode, i.e., when they access published information. One-seventh of the users (educational assignment performers) take an active position, preparing and posting educational assignments on the portal. However, these are completed at the teacher's request. A higher degree of activity is conducted by the group of activists for communication and document exchange, which comprises almost a third of all active users. These users, on their own initiative, interact with other users of the portal communities, utilizing the advantages of private messaging, document exchange, and publication status. Community organizers represent the smallest, although the most active, segment of the users. These users engage in high levels of activity in terms of both current work on the portal and other users' work organization.

However, the introduced classification of user groups is not a subordinate hierarchy. We cannot claim that these groups are the development levels of the educational portal communities, since each group has characteristics that distinguish it favorably from its "neighbors" not only in the lower, but also in the upper rows of the table (Figure 5).

For example, activists for communication and document exchange use course and group subscriptions more often than community organizers. They also work with training reports and tests on a more frequent basis. Comparing to the activists for communication, educational assignment performers use course subscriptions more often. In addition, they 
utilize the advantages of the tools for reporting and testing. In their turn, information consumers use the opportunities for establishing friendly relations and subscribing to groups more frequently than educational assignment performers. Only inactive users are excluded from this series, since all their indicators are lower in comparison to other groups.

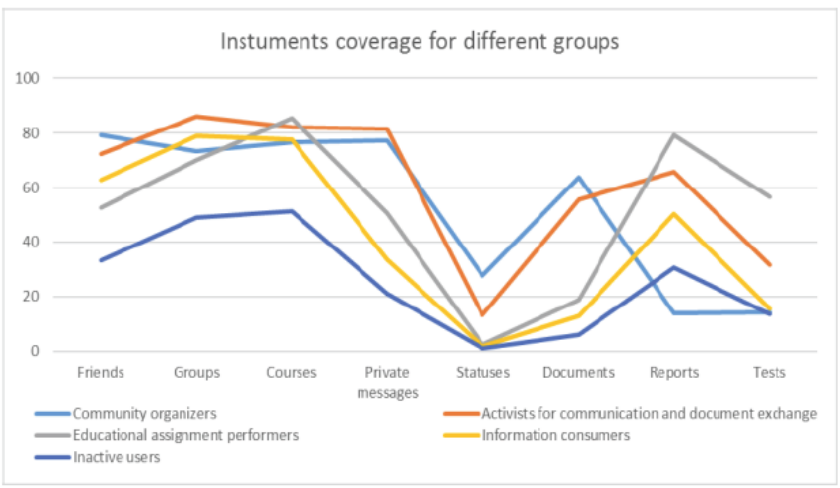

Figure 5: Comparison of indicators in terms of instruments utilization for different groups.

Therefore, the groups under research are distinguished as per the behavioral strategies. The users of these groups work with their goals by means of the tools that can be applied properly for solving the arising educational problems. According to the results obtained, further development of the portal as well as the similar educational resources, should be based on the idea that the design of universal tools, which are equally well suited for all users, is not effective.

In this regard, the development of new tools and the improvement of existing ones are necessary for providing proper support to the behavioral strategies that the users of different groups adhere to. Implementation, utilization, and application intensity of the proposed tools are determined by the implemented pedagogical technologies, namely: involving students into constructive and productive learning activities related to the development of new educational content, as well as the organization of open interaction in educational Internet communities. Therefore, it is necessary to develop new instrumental resources for community organizers, ensuring the distribution of new forms of education and the implementation of innovative pedagogical technologies.

This conclusion and the results of the study can be used in theoretical terms when developing projects for improving existing and creating new educational platforms that involve active work in Internet communities, as well as in the direct practice of developing software for relevant web applications, planning the application of these solutions in the field of education.

\section{ACKNOWLEDGEMENTS}

The Russian Foundation for Basic Research funded this study as per the research project No. 19-29-14064.

\section{REFERENCES}

Al-Azawei, A. (2019). What drives successful social media in education and e-learning? A comparative study on Facebook and Moodle. Journal of Information Technology Education: Research, 18, 253-274. https://doi.org/10.28945/4360

Aleksandrova, Ya., \& Parusheva, S. (2017). Social media in higher education from students' perspective. 4th International Multidisciplinary Scientific Conference on Social Sciences and Arts SGEM 2017, 709-716. https://doi.org/10.5593/sgemsocial2017/14/S04.092

Andreev, A. A. (2011). Pedagogy in information society or electronic pedagogy. Higher education in Russia, 11, 113-117.

Bykov, V. Y., \& Litvinova, S. G. (2016). Corporate social networks as an object of management education social system. Theory and practice of social systems management: philosophy, psychology, pedagogy, sociology, 2, 68-76.

Carmichael, P. (2011). Networking Research: New Directions in Educational Enquiry. Bloomsbury Publishing.

FICCI Higher Education Committee. (2017). Leapfrogging to Education 4.0: Student at the core. November 2017. FICClEY Future of Skills and Jobs. https://www.ey.com/ Publication/vwLUAssets/ey-leap-forgging/\$File/ey-leapforgging.pdf

Ivanko, A. F., Ivanko, M. A., \& Sinitsyna, A. O (2019). Experiences of educational social networks development. Scientific review. Pedagogical sciences, 6, 86-90. https://doi.org/10.17513/srps.2255

João Ferreira, M., Moreira, F., Santos Pereira, C, \& Durão, N. (2015) The role of mobile technologies in the teaching/learning process improvement in Portugal. Proceedings of ICERI2015 Conference 16th-18th November 2015, Seville, Spain, 46004610.

Kalischuk, S. A. (2017). Social networks as a means of social communication in an educational environment. Human capital, 9(105), 52-54.

Khutorskoy, A. V. (2019). Digital learning today. Bulletin of the Institute for Human Education, 1, 10.

Klopp, M., Abke, J. (2018). 'Learning 4.0': A Conceptual Discussion. 2018 IEEE International Conference on Teaching, Assessment, and Learning for Engineering (TALE), 4-7 December 2018. https://doi.org/10.1109/TALE.2018.8615244

Lebedeva, M. B. (2015). Massive open online courses as an education development trend. Man and education, 1(42), 105-108.

Manca, S. (2020). Snapping, pinning, liking or texting: investigating social media in higher education beyond Facebook. The Internet and Higher Education, 44, 100707. https://doi.org/10.1016/j.iheduc. 2019.100707

Marquis, J. (2017). 7 Ways Twitter Promotes 21st Century Learning. http://www.teachthought.com/social-media/7-ways-twitterpromotes-21st-century-learning/

Mikhailichenko, A. S., \& Vitkevich, R. V. (2019). Social networks as an element of the educational environment in a modern school. Modern education: topical issues, achievements and 
innovations. Collection of articles of the 33rd International Scientific and Practical Conference, 101-103.

Mikropoulos, T. A., \& Natsis, A. (2011). Educational virtual environments: A ten-year review of empirical research (19992009). Computers and Education, 56(3), 769-780. https://doi.org/10.1016/j.compedu.2010.10.020

Patarakin, E. D. (2017). A macroscopic approach to the analysis of joint network activities. Educational technologies, 2, 51-65. http://ifets.ieee.org/russian/depository/v20_i3/pdf/8.pdf

Sebo, M. (2016). Comparison of LMS and Facebook in terms of education support. 3rd International Multidisciplinary Scientific Conference on Social Sciences and Arts SGEM 2016. Conference proceedings, 125-132.
Sebo, M., \& Haskova, A. (2020). How students perceive educational support through Facebook. Education and Self-Development, 15(3), 67-75. https://doi.org/10.26907/esd15.3.06

Tkachenko, I. S., \& Bogatyreva, Yu. I. (2017). The use of social networks in educational process. Scientific result. Pedagogy and psychology of education, 3, 44-50. https://doi.org/10.18413/2313-8971-2017-3-3-44-50

Vlasova, A. A. (2018). Social networks as part of the modern digital educational environment of the university. Actual problems of improving higher education. Materials of the 13th scientific and methodological conference with international participation. Yaroslavl: P. G. Demidov Yaroslavl State University Publishing House.

DOI: https://doi.org/10.6000/1929-4409.2021.10.12

(C) 2021 Aleksei N. Sergeev; Licensee Lifescience Global.

This is an open access article licensed under the terms of the Creative Commons Attribution Non-Commercial License (http://creativecommons.org/licenses/by-nc/3.0/) which permits unrestricted, non-commercial use, distribution and reproduction in any medium, provided the work is properly cited. 